\title{
Spatial and size distributions of garnets grown in a pseudotachylyte generated during a lower crust earthquake
}

\author{
Adriane Clerc ${ }^{1,2}$, François Renard ${ }^{1,3}$, Håkon Austrheim $^{1}$, Bjørn Jamtveit ${ }^{1}$ \\ ${ }^{1}$ The NJORD Center, Physics of Geological Processes, Department of Geosciences, University of \\ Oslo, Norway \\ ${ }^{2}$ Institut de Physique du Globe de Strasbourg, CNRS, Université de Strasbourg/EOST, Strasbourg \\ France \\ ${ }^{3}$ Univ. Grenoble Alpes, Univ. Savoie Mont Blanc, CNRS, IRD, IFSTTAR, ISTerre, 38000, Grenoble, \\ France
}

\begin{abstract}
In the Bergen Arc, western Norway, rocks exhumed from the lower crust record earthquakes that formed during the Caledonian collision. These earthquakes occurred at about 30-50 km depth under granulite or amphibolite facies metamorphic conditions. Coseismic frictional heating produced pseudotachylytes in this area. We describe pseudotachylytes using field data to infer earthquake magnitude $(\mathrm{M} \geq \sim 6.6)$, low dynamic friction during rupture propagation $\left(\mu_{\mathrm{d}}<0.1\right)$ and laboratory analyses to infer fast crystallization of microlites in the pseudotachylyte, within seconds of the earthquake arrest. High resolution 3D X-ray microtomography imaging reveals the microstructure of a pseudotachylyte sample, including numerous garnets and their corona of plagioclase that we infer have crystallized in the pseudotachylyte. These garnets 1) have dendritic shapes and are surrounded by plagioclase coronae almost fully depleted in iron, 2) have a log-normal volume distribution, 3) increase in volume with increasing distance away from the pseudotachylyte-host rock boundary, and 4) decrease in number with increasing distance away from the pseudotachylyte -host rock boundary. These characteristics indicate fast mineral growth, likely within seconds. We propose that these new quantitative criteria may assist in the unambiguous identification of pseudotachylytes in the field.
\end{abstract}

Keywords: lower crust, earthquake; pseudotachylyte; garnet; Bergen Arc

\section{Highlights}

- $\quad$ Source parameters of $M \geq \sim 6.6$ lower crust fossil earthquakes estimated

- Coseismic slip produced a melt layer (pseudotachylyte) with extreme lubrication

- Garnet grew in the pseudotachylyte within seconds after the earthquake

- The shape, size and spatial distribution of these garnets provide additional criteria to recognize pseudotachylytes 


\section{Introduction}

Lower crust earthquakes occur between $30 \mathrm{~km}$ and $70 \mathrm{~km}$ depth in convergent boundaries such as subductions zones and mountain collision belts. The Bergen Arc, Western Norway, the focus of the present study, was a subduction zone active during the Caledonian orogeny, $420 \mathrm{Ma}$ ago. Exhumation brought rocks from the lower crust to the surface, and during the Quaternary glaciations ice polished the rocks, thus providing exceptional surface exposures.

Rocks of the Bergen Arc record earthquakes, which appear in the field as single ruptures in which a layer of dark material, recognized as pseudotachylyte, was formed during the propagation of the earthquake (Austrheim and Boundy, 1994). The pseudotachylyte then lubricated the slip surface. Since the study of Sibson (1975), several microstructural criteria have been proposed to define pseudotachylytes as veins created by frictional melting during a seismic event (e. g. Sibson and Toy, 2006 and references therein). Previous studies have identified the pseudotachylytes from the Bergen Arcs, Norway, from 1) their amorphous-like and dark aspect, 2) the presence of lateral injection veins, 3) the presence of chilled margins, 4) offsetting of structural markers along a sharp interface indicative of localized slip, and 5) their rapid cooling supported by the mineralogy (Austrheim et al., 1996; Bjørnerud et al., 2002). However, because aseismic shear (creep) can also produce amorphous material (Pec et al., 2012), the above five criteria might not be sufficient when considered independently to recognize pseudotachylytes produced by dynamic ruptures. These pseudotachylytes are similar to another study where initial fractures evolved into shear zones (Menegon et al., 2013). However, they differ from pseudotachylytes where initial planar heterogeneities, such as biotite trails, could act as nucleation sites for shear zones (Mancktelow and Pennacchioni, 2013) because we could not observe such initial heterogeneities on the field.

The earthquakes that formed these pseudotachylyte nucleated close to the Moho at 30 to $50 \mathrm{~km}$ depth (Bjørnerud et al., 2002; Austrheim, 2013) where the overall recorded worldwide seismicity decreases, where fossil earthquakes are rarely reported, and where earthquake source parameters are challenging to identify. The present study characterizes these elusive fossil earthquakes using field data, microscopy imaging and 3D microtomography imaging. From the analysis of microstructural data, we hypothesize that garnet crystals in the pseudotachylyte nucleated and grew during rapid cooling of the melt after rupture arrest. We quantify the microstructure, and spatial and size distributions of the newly formed garnets and propose that these observations provide an additional criterion to recognize pseudotachylytes in the field.

\section{Methods}

\subsection{Geologic setting and field data}

We acquired field data of pseudotachylytes at three outcrops of lower crust rocks on Holsnøy Island (eclogite metamorphism) and Lindås peninsula (amphibolite metamorphism), Western Norway. These 
outcrops of lower crust belong to the Bergen Arcs where the Caledonian collision thickened and deeply transformed the granulites of the Precambrian continental crust into amphibolite or eclogite facies rocks. Aqueous fluids infiltrated the subducted rocks (Austrheim and Griffin, 1985; Bjørnerud et al., 2002) and these water-rich fluids, which are presumed to have been transported through shear or fault zones, were responsible for the hydration of the dry granulite crust into eclogites and amphibolites. This process, which requires high pressure $(1.8-2.1 \mathrm{GPa})$ and temperature $\left(650^{\circ} \mathrm{C}\right)$ conditions, destabilized the plagioclase, and nucleated garnet, omphacite, amphibole, kyanite, zoisite, phengite, and minor quartz minerals. The eclogitization consumed water and alkaline minerals and released silica (Jamtveit et al., 1990).

The outcrops on Holsnøy Island have been described previously as hosting widespread occurrences of pseudotachylyte that record lower crust earthquakes (Fig. 1a, see also Austrheim et al. 1996; Austrheim and Boundy, 1999; Bjørnerud et al., 2002; Austrheim et al., 2017; Putnis et al., 2018). Similar pseudotachylytes have been observed in other localities to the North, near Måløy (Lund and Austrheim, 2003). The three outcrops on Holsnøy Island and Lindås peninsula, subsequently referred to herein as the Ådnefjell, Eldsfjellet, and Isdal, pseudotachylytes (Table 1), contain granulite rocks that evolved into amphibolite facies for the Isdal outcrop, and into eclogite facies for the other two outcrops. Pseudotachylytes are not easy to identify on the outcrops, as they might follow the foliation (Figs. 1b, 1c), and have a similar dark color as pyroxenite seams (Figs. 1b, 1c, 1e) and scapolite veins. Consequently, we used additional criteria to identify them in the field, including: the presence of lateral injection veins, the existence of offset markers, such as seams or pyroxenite layers, and a localized slip zone. In the Eldsfjellet outcrop (Austrheim et al., 1996), we observed a 10-cm thick intense brecciated damage zone on one side of the pseudotachylyte vein (Fig. 1b). Such breccias zones are consistent with the major damage undergone by the rock, probably due to local dilation, when the rupture propagated. This brecciated zone is also partially filled with recrystallized melt and therefore is directly related to the earthquake. In the fault walls, garnets located several millimeters away from the Ådnefjell pseudotachylyte show intense damage, that Austrheim et al. (2017) suggest was produced by coseismic dynamic strain. In order to characterize the slip and energy dissipated during earthquakes, we measured the thickness of pseudotachylytes every $10 \mathrm{~cm}$ with a caliper, with an error of $0.1 \mathrm{~mm}$, over distances up to $10 \mathrm{~m}$ (Fig. 1b, 1c). We measured their strike and dip and the foliation of the host rock (Table 1). We also reported the position and length of the observed injection veins. We collected hand specimens and core samples (diameter $5 \mathrm{~cm}$ ) in order to extract samples for microstructural characterization and measured the dip of the strain markers offset by the fault.

\subsection{Mineral composition maps}

Thin sections of the Eldsfjellet and Isdal pseudotachylytes were cut, carbon coated, and used for mineral composition analysis and high resolution imaging. We performed optical microscopy observations and X-ray fluorescence imaging of major elements at the ISTerre laboratory, University Grenoble Alpes, France (Figs. 2, 3). We acquired electron microprobe chemical maps of Al, Mg, Mn, 
$\mathrm{Ca}, \mathrm{Na}, \mathrm{Fe}, \mathrm{Si}$ and $\mathrm{K}$ at the University of Oslo, with a beam size of $2 \mu \mathrm{m}$, a voltage of $15 \mathrm{keV}$ and current of $30 \mathrm{nA}$, using wavelength-dispersive spectroscopy. Distance between points was $2 \mu \mathrm{m}$,

112 larger than the activation volume of the electron beam. We chose one garnet and its corona of

113 dendritic plagioclases for chemical mapping because it is representative of garnets and coronae

114 observed in the thin section cut in the Isdal sample (Fig. 4). From the X-ray microfluorescence

115 imaging and electron microprobe analysis, we calculated maps of minerals (Figs. 2b, 4a) using the

116 XMapTools software (Lanari et al., 2014). More detailed compositions of neo-formed dendritic

117 garnets of the Eldsfjellet outcrop can be found in the Table 2 of Austrheim et al. (1996).

\section{$118 \quad 2.3 \mathrm{X}$-ray microtomography imaging and processing}

119 We acquired one X-ray microtomography scan of the Isdal pseudotachylyte at the beamline ID19 at 120 the European Synchrotron (Grenoble, France). The sample had a rectangular shape, $2 \times 2 \times 4 \mathrm{~cm}^{3}$,

121 centered on the pseudotachylyte and was cut from a hand sample. The X-ray tomography scan was

122 performed by scanning a volume of interest inside the sample (i.e. local tomography) at $30 \mathrm{keV}$. The

123 voxel size $(4.66 \mu \mathrm{m})$ is close to the spatial resolution. We chose this sample because it contains a

124 millimeter-size pocket of pseudotachylyte enriched in garnet and plagioclase minerals that we interpret

125 to have crystallized fast during the cooling of a melt (Figs. 3a, 5), as proposed in previous studies

126 (Austrheim and Boundy, 1994; Austrheim, 2013). In this pocket, a larger number of garnets are

127 present and the garnet grain size distribution spans a wider range than in the rest of the

128 pseudotachylyte.

129 We analyzed the shape, size and spatial distribution of these neo-crystallized minerals in 2D sections

130 and 3D volumes using two image processing software packages: the open source multi-dimensional

131 image analysis software FiJi, and the commercial image processing software AvizoFire. Using two

132 different algorithms allows comparison of difference between corresponding results from each

133 algorithm. When both methods return similar results, we consider them robust. The procedure of

134 segmentation to extract the garnets and the coronae follows methods from previous studies that image

135 minerals in three dimensions in metamorphic rocks (Denison and Carlson, 1997; Ketcham, 2005;

136 Goergen and Whitney, 2008; Macente et al., 2017). The total volume was processed using only the

137 user-dependent workflow (AvizoFire), as the user-independent algorithm (FiJi) required too much

138 memory on the desktop computer used for the present study.

139 The FiJi software contains Weka segmentation (Arganda-Carreras et al., 2017), which is a machine

140 learning algorithm. This algorithm is based on the selection of a finite number of training classes by

141 the user, which are considered representative of the different phases in the image. Then these classes

142 are used by the machine learning algorithm to segment automatically the image. As a first step, we

143 identified three classes based on their grey-scale levels, the garnets and their corona, the

144 pseudotachylyte matrix and the host rock. Secondly, we selected a number of filters. We found that

145 three filters is the best compromise between efficiency of the calculation and accuracy because no

146 significant changes in the results could be measured when adding more than three filters. We used the 

volumes. Once the training was finished, the images with the three phases were extracted and thresholded to separate the garnets and their corona, the pseudotachylyte matrix, and the host rock (Fig. 6). Finally, the spatial position and volume of each garnet or garnet plus corona were labeled and we used these data for further statistical characterization. To extract the garnets and their coronae from the 3D volume, we used AvizoFire to filter and threshold the grey level values in the tomography scan, which indicate X-ray adsorption and are proportional to electron density. For this purpose, we developed a workflow based on thresholding the elements of interest and a system of masks. First, we segmented the pseudotachylyte area or volume by grey level thresholding. This thresholding was efficient because the X-ray adsorption of the pseudotachylyte matrix is defined by a well-defined range of grey levels in the 3D volume. We applied three successive filters (filling, eroding, dilating) to eliminate asperities, little particles or holes in the pseudotachylyte data (Fig. 6). Secondly, we masked the original image to hide the host rock so that the analysis only considers the pseudotachylyte vein. Thirdly, we selected the garnet crystals, and their coronae by simple grey scale thresholding. We used three different grey level thresholds: one for the garnet cores that showed very bright colors as it was the densest phase, one for the coronae which showed darker grey levels, and one for cracks which appeared dark. Finally, similar to the machine learning method, we saved the location and corresponding volume of each garnet, or garnet and corona as further inputs for statistical analyses and 3D rendering. With these two approaches, the garnet segmentation was not complete because the method identifies small garnets located near each other (i.e. within the spatial resolution of the measurement) as a single larger garnet. This issue is one of the few limitations of the method. We applied an additional procedure to reduce this effect, involving three steps. Firstly, a Gaussian filter with a standard deviation of 3 was used to blur the edges. Secondly, a pixel intensity threshold was applied to separate the objects from the background. Thirdly and finally, a watershed algorithm was run to separate the garnets (Fig. 7). This method is robust for roughly spherical objects, which is the case here (see Fig. $5 \mathrm{c})$. We applied this watershed step to the two segmentation methods described previously.

\section{Results}

\subsection{Field data}

We focused on two pseudotachylytes (Ådnefjell, and Eldsfjellet) with which we could unambiguously measure the apparent displacement and thickness over several meters (Fig. 1c, 1d). We interpret them as singular earthquakes. This assumption is supported by the observations that 1) one pseudotachylyte layer, not several, was observed at each location, 2) we did not observe clasts of prior pseudotachylytes dragged in the pseudotachylytes, 3) the outcrops expose few neighboring injection veins, and 4) the injections veins do not appear to be cut by a second set of injection veins that would have been produced by a later earthquake. Moreover, rock melting and subsequent solidification 
strengthens crustal rock (Mitchell et al. 2016), and therefore lower crustal earthquakes are not expected to occur repeatedly in the same location.

The total apparent offset could be measured because these two pseudotachylyte-bearing faults cut and offset pyroxenite seams, with apparent offsets of $0.55 \mathrm{~m}$ and $0.60 \mathrm{~m}$ (Table 1). The apparent displacement represents a minimum value for the total slip on the faults because we did not find markers of the direction of slip such at slickenlines of flow banding or brushline structures (Ferre et al., 2016), which would allow calculation of the net slip. Using the measurement of the position, dip and strike of the slip planes, and apparent thickness we calculated pseudotachylyte actual thickness, after correcting for the dip and for the small volume of injection veins $(\leq 5 \%)$. Given that the orientation and thickness of the pseudotachylytes can change slightly along strike, we calculated an average thickness in the range 1-5 $\mathrm{mm}$ (Table 1). Several other smaller faults are decorated with a pseudotachylyte layer, and have smaller offsets in the same area, indicating active brittle deformation at the scale of several kilometers (Fig. 1a, see also Austrheim et al., 1996). We interpret these observations as singular earthquakes with lower magnitudes.

\subsection{Mineral composition maps}

X-ray fluorescence processed data reveal different minerals of the thin section from the Eldsfjellet outcrop (Fig. 2b, c), which is representative of the other outcrops. The granulite host rock is mainly an anorthosite which contains seams with clinopyroxenes and garnets. We hypothesize that the initial pseudotachylyte was a melt because of the presence of injection veins on the walls. The pseudotachylyte has then recrystallized during cooling and contains now a matrix and few fragments of the host rock that became entrain during earthquake. These fragments represent $\leq 5 \%$ of the total pseudotachylyte volume. Some fragments of scapolite highlight the boundary between the pseudotachylyte and the host rock, and indicate that this silicate was fragmented during the rupture and later accumulated at the pseudotachylyte -host rock interface (Fig. 2b). Locally, the composition of the pseudotachylytes may depend on the wall rock. For example, sulfides (Fig. 3f) are only found where scapolite is present in the wall (Fig. 2b).

We acquired complementary optical and scanning electron microscopy images to explore the composition of the pseudotachylytes (Figs. 2c, 2d, 3). The Isdal thin section shows the presence of dendritic and skeletal garnets, with a corona of plagioclase surrounding them in the pseudotachylyte (Fig. 3e), which we interpret to have crystallized during cooling of the melt in the seconds after the rupture propagated (Austrheim et al., 1996). Microtomography data and electron microprobe data show similar observations (Figs. 4, 5). These garnets show no evidence of flow banding around them (Figs. 2c, 3b, 3d). Consequently, they formed probably immediately after earthquake propagation, and when the melt was immobile.

Electron microprobe data show that the garnet cores are dendritic and/or skeletal (Figs. 2c, 2d, 3e, 4a), with cavities filled with microlites, enriched in iron, and without chemical zoning. Note that for the 
Ednefjellet sample, some zoning was previously observed (see Fig. 15 in Austrheim et al., 1996). In the Isdal sample, a corona of iron-depleted matrix where dendritic plagioclase minerals have grown surrounds each garnet (Figs. 3e, 4). We interpret these observations as indicative of a rapid and incomplete growth of the garnet core and the corona. The pseudotachylyte matrix is composed mainly of plagioclase and amphibole and contains small amounts of quartz and kyanite recognized by point analyses. We characterize the iron depletion zone with a concentration profile across the garnet (Fig. $4 \mathrm{c})$. This profile shows iron enrichment within the garnet and almost full iron depletion in the corona relative to the pseudotachylyte matrix. The average iron concentration in a profile across the garnet and the average from a profile of the same length in the pseudotachylyte matrix are equal (Fig. 4c). We interpret this equality as indicative of mass conservation of iron at this scale, suggesting a closed system for this element. Thus, the garnets incorporated most of the iron surrounding them during their growth, and the iron-depleted plagioclase corona highlights the depletion zone.

\subsection{Grain size distribution of neo-formed garnets}

We characterized the size and spatial distribution of the garnets in the pseudotachylyte using the X-ray tomography data. From the core recovered from the field, we extracted four 2D images and four 3D sub-volumes for analysis. Grain size distributions are plotted, and fitted with three different statistical laws (Fig. 8): Gaussian, log-normal or power law. Past studies attribute grain size distribution laws to unique genetic processes. A log-normal law has been proposed to characterize the nucleation and growth of crystals (Teran et al., 2010). The power law describes grain size distribution in a rock that has undergone rapid fragmentation ( $\AA$ ström et al., 2004). We measured the accuracy of the fit by the $\mathrm{R}^{2}$ value. The $\mathrm{R}^{2}$ varies in relation to the volume or slice studied, the method, or the object segmented (garnet cores alone or with the coronae). In all cases, a log-normal distribution best describes the data (Fig. 8$)$. Because the resolution of the 3D image is limited $(4.66 \mu \mathrm{m})$, very small elements may not have been counted. Thus, the data histogram is incomplete when tending towards small grain sizes. The log-normal distribution could tend to an exponential distribution if our methods could identify these small grain sizes. Nevertheless, on the basis of statistics achieved on the $\mathrm{R}^{2}$ of each fit, we propose that a log-normal distribution describes the data better than a power law. We study now the spatial distribution of the garnets cores and coronae (Fig. 9). For this purpose, we calculated the distance of each element (garnet cores with or without coronae) to the closest border of the pseudotachylyte, i.e. nearest wall rock (Figs. 9c, 9d, 9f). Both 2D and 3D analyses confirm that the spatial density of garnets decreases from the contact with the host rock to the center of the pseudotachylyte (Figs. 8, 9c, 9d, 9e, 9f), with larger garnets located in the middle of the pseudotachylyte (Fig. 5b). Bjørnerud et al., (2002) qualitatively describes this distribution as well in a similar pseudotachylyte. In addition, we studied the combined spatial and size distributions to see if any trend could be identified. A cloud of points is constructed to represent the distance to the nearest host rock wall and the size of the garnets and coronae (Figs. 9, 10). Fig. 10 shows the positive gradient of garnet and coronae sizes towards the center of the pseudotachylyte. 
Despite some differences in the detected number of garnets and coronae, the user-dependent and userindependent segmentation workflows produce similar results: a log-normal grain size distribution, with a potential exponential distribution when smaller grains are included, a grain size gradient from the host rock to the center of the pseudotachylyte, and a larger number of nucleated grains at the boundary with the host rock.

\section{Discussion and Conclusion}

\subsection{Magnitude and rupture propagation of the Bergen Arc lower crust earthquakes}

We estimate the earthquake magnitude from structural markers offset by earthquakes, and the assumption that each pseudotachylyte represents a single earthquake. Two of our pseudotachylytes are traced over several tens of meters. The offset markers measured on the Ådnefjell and the Eldsfjellet outcrop faults show minimal left lateral apparent displacements of $0.55 \mathrm{~m}$ and $0.6 \mathrm{~m}$, respectively (Figs. 1c, 1d). We consider that these offsets are entirely produced during the earthquake, and that post-seismic creep in the pseudotachylyte can be neglected because the thin sections did not show any creep around clasts of host rock embedded into the pseudotachylyte. Using established scaling relationships between displacement and earthquake magnitude (Wells and Coppersmith, 1994), one can estimate the magnitude of fossil earthquakes based on total slip. In this calculation, we consider two uncertainties: the faulting mode and the total offset. As these earthquakes occurred in the lower crust in a context of subduction and collision, either strike-slip or reverse displacements could have occurred. Oblique reverse motion may also have occurred, but in subduction zones, strain is more often partitioned into convergent, trench perpendicular (reverse) motion and trench parallel (strike slip) motion on several faults, rather than oblique slip on one fault plane (Fitch, 1972). We observed one unambiguous displacement marker for each earthquake, and the corresponding measured offset represents either a minimum or average value for the total slip. We estimate the earthquake magnitude using the scaling relationships for strike-slip and reverse faulting, and for the maximum and the average offsets (Table 2B in Wells and Coppersmith, 1994). The minimum average magnitude for both outcrops is similar $(\mathrm{M} \geq 6.6 \pm 0.2)$, due to the similar apparent displacement. In the field, the pseudotachylytes veins are sometimes located at the interface between the granulite host rock and a pyroxene-garnet seam (Figs. 1c, 1e). The numerical study of Bietzke and Ben-Zion (2006) considered rupture propagation within a solid composed of three layers. If the rupture direction is close enough to the direction of the interface $\left(<30^{\circ}\right)$, a rupture nucleating in the middle of one of the three layers tends to migrate towards the nearest material interface. Their numerical results could explain why some ruptures oriented almost parallel to the foliation tend to localize along the boundary with pyroxene-garnet seams. However, if the angle between the fault and the foliation is too high (Fig. 1d), ruptures may not localize along this boundary.

\subsection{Shear stress during slip and fault lubrication}


Source parameters of earthquakes can be inferred when measurable field and rock physics parameters are available such as the rupture length, the rupture width, the surface displacement, and the material properties of the rocks and melt (Di Toro et al., 2005). The conversion of strain energy to frictional dissipation during slip produces a phase transformation, from solid to melt, forming pseudotachylytes veins. Using a simple energy budget approach, the thickness of a pseudotachylyte can be related to the amount of slip and the state of stress at the interface (Sibson, 1975; Sibson and Toy, 2006; Nielsen et al., 2008; Beeler et al., 2016). To utilize this approach, the temperature and pressure conditions in the granulites, as well as material properties and slip velocity must be inferred (Table 2). The depth of the earthquakes has been estimated from the mineralogy of recrystallized crystals in the pseudotachylytes, which is, in the eclogite domain, corresponding to 40-50 km depth (Austrheim, 2013). We calculate the static pressure using the bulk density of granulites equal to $3.02 \mathrm{~kg} \cdot \mathrm{dm}^{-3}$ (Austrheim, 1987), which falls in the range 1.2-1.5 GPa. The temperature at this depth has been estimated to be $920^{\circ} \mathrm{K}$ (Austrheim et al., 2017). The melting temperature of granulite is at least $1220^{\circ} \mathrm{K}$ for a confining pressure $\geq 1 \mathrm{GPa}$ (Vielzeuf and Vidal, 1992). We can also infer a minimal temperature reached by the melt because microscopic images show that scapolite minerals (Fig. 2b) had decomposed during slip and produced sulphides, which formed droplets that spread through the melt (Fig. 3f, see also Fig. 2B in Austrheim et al., 2017). The temperature of this decomposition is $1770{ }^{\circ} \mathrm{K}$ (Magloughlin, 2005), which we consider here as the maximum temperature reached in these pseudotachylytes. Other material properties, such as heat capacity $\left(c_{p}\right)$, latent heat of fusion $(H)$, and thermal diffusivity $(\kappa)$ of the host rock are required to calculate the dynamic shear stress during slip. To our knowledge, there are no available values for these parameters for the granulites studied and, as a result, we decided to use those of gabbro, which has a chemical composition and density close to those of granulites. These parameters for a gabbro and for the melt are given in Nielsen et al. (2010). Finally, a rupture velocity of $1 \mathrm{~m} \cdot \mathrm{s}^{-1}$ was chosen, as in previous studies (Nielsen et al., 2008, 2010).

The dynamic shear stress during coseismic slip $\left(\tau_{d}\right)$ can be derived from an energy balance where the energy of melting is proportional to stress and surface displacement (Nielsen et al, 2008):

$$
\tau_{d} * \frac{d}{w}=(1-\phi) * H+c_{p} *\left(T_{m}-T_{h r}\right),
$$

where $d$ is the total displacement (m), $w$ is the pseudotachylyte thickness $(\mathrm{m}), \phi$ is the fraction of host rock clasts in the pseudotachylyte (dimensionless), $T_{m}$ is the melt temperature ( ${ }^{\circ} \mathrm{K}$ ), and $T_{h r}$ is the temperature of the host rock $\left({ }^{\circ} \mathrm{K}\right)$. We assume that there is no extrusion of melt during slip (i.e. melt is not released out of the fracture). This assumption applies to the pseudotachylytes described in the present study where the total volume of extrusion veins represents $\leq 5 \%$ of the volume of pseudotachylytes estimated from outcrops. Consequently, we consider that all the heat produced by friction was dissipated at the fault interface during slip. Another hypothesis is that the heat capacities of the host rock and of the melt are similar (Nielsen et al., 2008). By applying this relationship to 
Ådnefjell and Eldsfjellet outcrops (Figs. 1b, 1c, 1d), we calculate a dynamic coseismic shear stresses of $7 \mathrm{MPa}$ and $30 \mathrm{MPa}$, respectively.

We estimate the state of stress prior to the earthquake by assuming that the pressure is equal to the vertical overburden, and a Coulomb failure criterion is applicable at the onset of rupture. The total pressure $P_{v}$ is equal to $\rho \cdot g \cdot z$, where $\rho$ is the density, $g$ the gravity constant and $z$ the depth. On the fault plane, this total pressure can be decomposed into a normal stress, $\sigma_{n}$, and a static shear stress, $\tau_{s}$, using the fault dip. We assume the fault is oriented at an angle $\alpha$ to the main compressive stress, taken here equal to $\mathrm{P}_{\mathrm{v}}$ and a typical Coulomb ratio of $\tau_{s} / \sigma_{n}$, which is equal to $\tan (\alpha)=0.7$ at failure, assuming that the fault surface has no cohesion. This corresponds to an angle $\alpha=28^{\circ}$ and a static shear stress $\tau_{s}=$ $\mathrm{P}_{\mathrm{v}} \cdot \sin (\alpha)$ in the range 600 to $750 \mathrm{MPa}$. Consequently, the ratio between the static and dynamic shear stress represents the efficiency of weakening during slip, and is estimated in the range 20 to 100 . The dynamic friction coefficient, $\mu_{d}=\tau_{s} / \sigma_{n}$ is therefore estimated in the range 0.005 to 0.07 . Such lubrication effect is in agreement with experiment studies that show a strong decrease of the dynamic friction coefficient at seismic slip velocities, down to values close to 0.1 (Di Toro et al., 2011).

\subsection{Garnet growth during the cooling of a pseudotachylyte}

The two arguments that the garnets must have grown very fast in a melt are that 1) the presence of dendritic garnets, 2) these garnets are skeletal and lacunar (another effect of dendritic growth), which allows sub-micrometer microlites to nucleate inside. If one considers the coefficient of diffusion in a melt at $1770^{\circ} \mathrm{K}$ to be in the range $\mathrm{D}=10^{-10}-10^{-9} \mathrm{~m}^{2} \cdot \mathrm{s}^{-1}$ (Baker et al., 2005), the characteristic diffusion length scale $\mathrm{d}_{\text {diff }}$ over $\mathrm{t}=1 \mathrm{~s}, \mathrm{~d}_{\mathrm{diff}}=(\mathrm{Dt})^{0.5}$ is in the range 10-30 $\mu \mathrm{m}$. Over $\sim 10 \mathrm{~s}$ of cooling, this would correspond to diffusion length scales of 30-100 $\mu \mathrm{m}$, on the same orders of magnitude of the length scales observed for garnet and corona growth in the pseudotachylytes.

We calculate the cooling rate of the pseudotachylytes using an analytical solution of the heat diffusion equation for a thin layer of melt (Carslaw and Jaeger, 1959; Boullier et al., 2001). Given that the length of the pseudotachylyte is several orders of magnitude larger than its thickness, a 1D problem is considered for a semi-infinite solid such that the variation in temperature with distance and time is:

$$
T(x, t)-T_{h r}=\frac{1}{2} *\left(T_{m}-T_{h r}\right) *\left\{\operatorname{erf}\left[\frac{a\left(1-\frac{x}{a}\right)}{2(\kappa t)^{\frac{1}{2}}}\right]+\operatorname{erf}\left[\frac{a\left(1+\frac{x}{a}\right)}{2(\kappa t)^{\frac{1}{2}}}\right]\right\}
$$

where $x$ is the distance to the center of the melt layer, $a$ is half the thickness of the melt layer $(\mathrm{m}), t$ is time (s), $T(x, t)$ is temperature at a distance $x$ and time $t$ from the center of the melt layer, $T_{m}$ is the temperature of the melt, $T_{h r}$ is the temperature of the surrounding rock $\left({ }^{\circ} \mathrm{K}\right)$, and $\kappa$ is the thermal diffusivity $\left(\mathrm{m}^{2} \cdot \mathrm{s}^{-1}\right)$. We calculate the cooling for the Adnefjell and Eldsfjellet outcrops. The halfthickness of the pseudotachylyte is $0.5 \mathrm{~mm}$ and $2.6 \mathrm{~mm}$, respectively and $T_{m}-T_{h r}=850{ }^{\circ} \mathrm{K}$. Because the Isdal pseudotachylyte formed in a granulite that was transformed under amphibolite conditions, the host rock temperature could have been smaller than the value of $870{ }^{\circ} \mathrm{K}$ considered here, therefore the estimated cooling rate represents a conservative maximum value. This approach 
gives cooling durations of the order of several seconds (Fig. 11). After $\sim 7 \mathrm{~s}$, the melt has reached its solidification point and we infer that garnets grew during this short period. This fast growth far from equilibrium induced the formation of dendritic and skeletal garnets with a surrounding corona which is almost fully depleted in iron and where plagioclase minerals grew (Figs. 2c, 2d, 3e, 4a). The segmentation of the garnet crystals and their plagioclase corona in the microtomography $3 \mathrm{D}$ image enables characterization of the grain size and spatial distributions of these crystals in the pseudotachylyte. Numerous small garnets are located near the boundary between the pseudotachylyte and the host rocks, whereas larger and fewer grains are located in the middle of the pseudotachylyte vein (Figs. 5b, 8, 9). The 3D analysis was focused on two sub-volumes of a small pocket of pseudotachylyte that stands out from the main pseudotachylyte. We used two unique image processing techniques to identify individual garnet crystal sizes. These techniques produce similar estimates of spatial and size distribution. Moreover, the segmentation of garnets with or without coronae produce similar distributions, suggesting the simultaneous formation of both garnets and plagioclase coronae. We propose that nucleation and growth occurred during the $\sim 7 \mathrm{~s}$ of cooling before the melt solidified (Fig. 11). This short duration is in the range of what has been proposed by Sawyer and Resor (2017), using a more complete model that takes into account cooling and flow. Teran et al. (2010) studied the time-dependent change in grain size distribution during nucleation and growth of crystals in a liquid. Using the Kolmogorov-Avrami-Mehl-Johnson grain growth model as well as an effective timedependent growth rate, these authors proposed that a log-normal grain size distribution is determined by the dimensionality of the growth process, and the time decay rates of nucleation and growth. Our analysis of the size distribution of garnets and coronae supports this conclusion. Because the melt cooled faster at the edges than in the middle of the pseudotachylyte, we infer that the nucleation rate was faster near the edges, producing larger numbers of garnet near the melt edges. Conversely, in the middle of the pseudotachylyte the cooling rate was slower, and the cooling duration was longer, producing a smaller number of garnets and larger average size.

Moreover, the distance of the garnets to the melt-host rock border could also influence the nucleation and growth of crystals via the availability of sites on which new crystals could nucleate. The pseudotachylyte border might be richer in nucleation sites such as small fragments of host rock, whereas the central fully melted part of the pseudotachylyte might be poorer in fragments of host rock. Therefore, the conditions of nucleation and growth vary as a function of the location in the melt phase (i.e., heterogeneous nucleation).

A pseudo log-normal garnet grain size distribution was observed previously in eclogites (Cheng et al., 2008). These authors suggested that episodes of garnet nucleation and growth by solid-state transformations during eclogitization of the rock produced this grain size distribution. However, this study did not observe spatial gradient in grain size nor spatial variation of nucleation within the host rock. Conversely, for the sample described in the present study, we find that 1) the garnet crystals follow a log-normal size distribution, 2) these garnets are skeletal and the coronae have a dendritic 
shape; and 3) their spatial distribution underlines a gradient in the number and size of crystals as a function of the distance to the border. We conclude that these crystals have nucleated and grew in the melt phase due to the significant rise in temperature despite a short cooling time, as it was proposed in a previous study (Austrheim et al., 1996). Our new observations provide circumstantial evidence of fast growth in the melt, which we propose as an additional criterion to recognize pseudotachylyte veins. This contrasts with slow creep sliding (Pec et al., 2012), where the rise in temperature might be a few degrees, which is not sufficient for crystals to grow fast.

Further studies should consider the garnet growth process more precisely in the pseudotachylytes studied. This would be a challenging task because the detailed kinetics of garnet growth in undercooled conditions is poorly understood. In the present study, the relationship between the garnet spatial distribution and characteristic size confirms the trend between grain size and distance to the boundary (Fig. 10), observed qualitatively previously (Bjørnerud et al., 2002). We obtain similar quantitative results with two segmentation methods. Moreover, segmenting either garnet cores alone or garnet cores and coronae, reveals similar trends in of the distribution of the grain size and distance to the nearest wall rock. These trends characterize the growth of the garnets in the melt vein, in a 420 Ma old fossil natural micro-reactor located at 30-50 km depth.

\subsection{A new microstructural criteria to recognize pseudotachylytes}

Analysis of pseudotachylytes from the Bergen Arc, Norway, can characterize earthquake source parameters of the lower crust fossil earthquakes that produced these pseudotachylytes. On the basis of field data, including apparent offsets, we suggest the magnitude of these earthquakes was larger than 6.6. By estimating the state of stress at depth, we calculate that the shear stress may have dropped to reach low dynamic friction coefficient $\mu_{\mathrm{d}}<\sim 0.1$ during these earthquakes. Frictional heating produced melt that lubricated the fault interface and so reduced the shear stress, as proposed in previous field and experimental studies (e. g. Di Toro et al., 2005; Nielsen et al., 2008, 2010). Previous observations of damage in the wall rock, presence of injection veins, and evidence of melting of sulphides (Austrheim et al., 2017), the description of the newly formed garnets (Austrheim and Boundy, 1999), and our new analyses suggest that these pseudotachylytes were produced during lower crust earthquakes.

In the literature, the most accepted definition of a "pseudotachylyte" is a cm-scale solidified frictional melt generated during slip on a fault plane (e.g., Sibson and Toy, 2006). The high velocity during slip, narrow localization, and high shear stress should increase the local temperature and so melt the host rock. Our analysis suggests that in the Bergen Arc, lower crust earthquakes cooled within seconds after earthquake arrest. As the melt cooled, dendritic and skeletal garnet and plagioclase coronae grew in the melt. We report that: 1) the size distribution of the neo-formed garnets follow a log-normal (or exponential) distribution, characteristics of mineral growth processes, 2) more numerous small garnets crystallized near the wall rock than further from the wall rock, and 3) whereas fewer but larger garnets formed in the middle of the pseudotachylyte. 
These observations suggest that additional microstructural criteria that we may use to identify pseudotachylytes along faults include the grain size and spatial distributions of newly formed minerals, as well as the microstructures and mineral geometry indicative of a fast growth.

Acknowledgements: We thank Elodie Boller at the European Synchrotron Radiation Facility for her help during the acquisition of the X-ray tomography images, Muriel Erambert at the University of Oslo for the acquisition of microprobe data, Benoit Cordonnier for helping with statistical distribution programming, and Jessica Ann McBeck for a careful review of the manuscript. Thanks are also due to Virginia Toy, Stefan Nielsen, Patrick Baud, and Wenlu Zhu for enlightening discussions on pseudotachylytes. We thank the Co-Editor-in-Chief, Dr. Kelin Wang, the Guest Editor Dr. Amir Sagy, and Dr. Florian Fusseis, Dr. John Geissman and one anonymous reviewer for advices that improved greatly the initial version of the manuscript. The present study received funding from the Norwegian Research Council (grant HADES, 250661) to FR and the European Union's Horizon 2020 Research and Innovation Programme under the ERC Advanced Grant Agreement n ${ }^{\circ} 669972$, 'Disequilibrium Metamorphism' ('DIME') to BJ.

\section{References}

Arganda-Carreras, I., Kaynig, V., Rueden, C., Eliceiri, K. W., Schindelin, J., Cardona, A., \& Sebastian Seung, H. (2017). Trainable Weka Segmentation: a machine learning tool for microscopy pixel classification. Bioinformatics, btx180, doi: 10.1093/bioinformatics/btx180.

Åström, J. A., Linna, R. P., Timonen, J., Møller, P. F., \& Oddershede, L. (2004). Exponential and power-law mass distributions in brittle fragmentation. Physical Review E, 70(2), 026104. Austrheim, H., \& Griffin, W. L. (1985). Shear deformation and eclogite formation within granulitefacies anorthosites of the Bergen Arcs, western Norway. Chemical Geology, 50(1), 267-281. Austrheim, H. (1987). Eclogitization of lower crustal granulites by fluid migration through shear zones. Earth and Planetary Science Letters, 81(2-3), 221-232.

Austrheim, H., \& Boundy, T. M. (1994). Pseudotachylytes generated during seismic faulting and eclogitization of the deep crust. Science, 265(5168), 82-84.

Austrheim, H., Erambert, M., \& Boundy, T. M. (1996). Garnets recording deep crustal earthquakes. Earth and Planetary Science Letters, 139(1-2), 223-238.

Austrheim, H. (2013). Fluid and deformation induced metamorphic processes around Moho beneath continent collision zones: Examples from the exposed root zone of the Caledonian mountain belt, WNorway. Tectonophysics, 609, 620-635.

Austrheim, H., Dunkel, K. G., Plümper, O., Ildefonse, B., Liu, Y., \& Jamtveit, B. (2017). Fragmentation of wall rock garnets during deep crustal earthquakes. Science Advances, 3(2), e1602067. 
Baker, D. R., Freda, C., Brooker, R. A., \& Scarlato, P. (2005). Volatile diffusion in silicate melts and its effects on melt inclusions. Annals of Geophysics, 48(4-5), 699-717.

Beeler, N. M., Di Toro, G., \& Nielsen, S. (2016). Earthquake Source Properties from Pseudotachylyte. Bulletin of the Seismological Society of America, 106, 2764-2776.

Bjørnerud, M.G., Austrheim, H. and Lund, M.G. (2002). Processes leading to eclogitization (densification) of subducted and tectonically buried crust. Journal of Geophysical Research, 107, B102252.

Boullier, A. M., Ohtani, T., Fujimoto, K., Ito, H., \& Dubois, M. (2001). Fluid inclusions in pseudotachylytes from the Nojima fault, Japan. Journal of Geophysical Research, 106(B10), 2196521977.

Brietzke, G. B., \& Ben-Zion, Y. (2006). Examining tendencies of in-plane rupture to migrate to material interfaces. Geophysical Journal International, 167(2), 807-819.

Carslaw, H. S., \& Jaeger, J. C. (1959). Conduction of heat in solids. Oxford: Clarendon Press, 1959, $2^{\text {nd }}$ Ed.

Cheng, H., Zhou, Z., \& Nakamura, E. (2008). Crystal-size distribution and composition of garnets in eclogites from the Dabie orogen, central China. American Mineralogist, 93(1), 124-133.

Denison, C. \& Carlson, W.D. (1997). Three-dimensional quantitative textural analysis of metamorphic rocks using high-resolution computed X-ray tomography: part II. Application to natural samples. Journal of Metamorphic Geology, 15, 45-57.

Di Toro, G., Pennacchioni, G., \& Teza, G. (2005). Can pseudotachylytes be used to infer earthquake source parameters? An example of limitations in the study of exhumed faults. Tectonophysics, 402(1), $3-20$.

Di Toro, G., Han, R., Hirose, T., De Paola, N., Nielsen, S., Mizoguchi, K., Ferri, F., Cocco, M., \& Shimamoto, T. (2011). Fault lubrication during earthquakes. Nature, 471, 494-498.

Ferré, E. C., Yeh, E. C., Chou, Y. M., Kuo, R. L., Chu, H. T., \& Korren, C. S. (2016). Brushlines in fault pseudotachylytes: A new criterion for coseismic slip direction. Geology, 44(5), 395-398.

Fitch, T.J. (1972). Plate convergence, transcurrent faults, and internal deformation adjacent to Southeast Asia and the western Pacific. Journal of Geophysical Research, 77, 4432-4460.

Goergen, E.T. \& Whitney, D.L. (2012). Corona networks as three-dimensional records of transport scale and pathways during metamorphism. Geology, 40, 183-186.

Jamtveit, B., Bucher-Nurminen, K., \& Austrheim, H. (1990). Fluid controlled eclogitization of granulites in deep crustal shear zones, Bergen arcs, Western Norway. Contributions to Mineralogy and Petrology, 104(2), 184-193.

Ketcham, R.A. (2005). Computational methods for quantitative analysis of three-dimensional features in geological specimens. Geosphere, 1, 32-41. 

XMapTools: a MATLAB $C$-based program for electron microprobe X-ray image processing and geothermobarometry. Computers and Geosciences. 62, 227-240.

Lund, M. G., \& Austrheim, H. (2003). High-pressure metamorphism and deep-crustal seismicity: evidence from contemporaneous formation of pseudotachylytes and eclogite facies coronas. Tectonophysics, 372(1), 59-83.

Macente, A., Fusseis, F., Menegon, L., Xianghui, X., \& John, T. (2017). The strain-dependent spatial evolution of garnet in a high-P ductile shear zone from the Western Gneiss Region (Norway): a synchrotron X-ray microtomography study. Journal of Metamorphic Geology, 35, 565-583.

Magloughlin, J. F. (2005). Immiscible sulfide droplets in pseudotachylyte: Evidence for high temperature $\left(>1200^{\circ} \mathrm{C}\right)$ melts. Tectonophysics, 402(1), 81-91.

Mancktelow, N. S., \& Pennacchioni, G. (2013). Late magmatic healed fractures in granitoids and their influence on subsequent solid-state deformation. Journal of Structural Geology, 57, 81-96.

Menegon, L., Stünitz, H., Nasipuri, P., Heilbronner, R., \& Svahnberg, H. (2013). Transition from fracturing to viscous flow in granulite facies perthitic feldspar (Lofoten, Norway). Journal of Structural Geology, 48, 95-112.

Mitchell, T. M., Toy, V. Di Toro, G., Renner, J. Sibson, R. H. (2016). Fault welding by pseudotachylyte formation, Geology, 44, 1059-1062.

Nielsen, S., Di Toro, G., Hirose, T., \& Shimamoto, T. (2008). Frictional melt and seismic slip. Journal of Geophysical Research: Solid Earth, 113, B01308.

Nielsen, S., P. Mosca, G. Giberti, G. Di Toro, T. Hirose, and T. Shimamoto (2010). On the transient behavior of frictional melt during seismic slip, J. Geophys. Res., 115, B10301.

Pec, M., Stünitz, H., Heilbronner, R., Drury, M., \& de Capitani, C. (2012). Origin of pseudotachylytes in slow creep experiments. Earth and Planetary Science Letters, 355, 299-310.

Putnis, A., Jamtveit, B., and Austrheim, H. (2017) Metamorphic processes and seismicity: the Bergen Arcs as a natural laboratory, Journal of Petrology, doi: 10.1093/petrology/egx076

Sawyer, W. J., Resor, P. G. (2017) Modeling frictional melt injection to constrain coseismic physical conditions. Earth and Planetary Science Letters, 469, 53-63.

Sibson, R. (1975). Generation of pseudotachylyte by ancient seismic faulting. Geophys. J. R. Astr. Soc. Lond. 43,775-794.

Sibson, R. H., \& Toy, V. G. (2006). The habitat of fault-generated pseudotachylyte: Presence vs. absence of friction-melt. In "Earthquakes: Radiated Energy and the Physics of Faulting”, Geophysical Monograph Series 170, 153-166.

Teran, A. V., Bill, A., \& Bergmann, R. B. (2010). Time-evolution of grain size distributions in random nucleation and growth crystallization processes. Physical Review B, 81(7), 075319. 
543 Vielzeuf, D., \& Vidal, P. (Eds.). (1992). Granulites and crustal evolution. Proceedings on the NATO

544 Advanced Workshop on "Petrology and Geochemistry of Granulites", Clermont Ferrand, France,

545 September, 5-9, 1988. Kluwer Academic Publisher, Dordrecht, The Netherlands.

546 Wells, D. L., \& Coppersmith, K. J. (1994). New empirical relationships among magnitude, rupture

547 length, rupture width, rupture area, and surface displacement. Bulletin of the seismological Society of

548 America, 84(4), 974-1002. 
550 Table 1: Pseudotachylyte outcrops located in the Bergen Arc area, Norway.

\begin{tabular}{|c|c|c|c|}
\hline & Isdal outcrop (Fig. 1e) & Ådnefjell outcrop (Fig. 1b,c) & Eldsfjellet outcrop (Fig. 1d) \\
\hline GPS coordinates & $\begin{array}{l}\text { N 60³3'28', } \\
\text { E } 5^{\circ} 15^{\prime} 51^{\prime \prime}\end{array}$ & 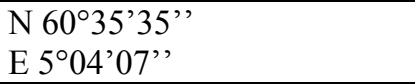 & $\begin{array}{l}\text { N } 60^{\circ} 35^{\prime} 33^{\prime \prime} \\
\text { E } 5^{\circ} 01^{\prime} 41^{\prime \prime}\end{array}$ \\
\hline Host rock & Granulite, amphibolite facies & Granulite, eclogite facies & Granulite, eclogite facies \\
\hline Sample reference & HSA2-11 & AF2-4 & A20-04 \\
\hline $\begin{array}{l}\text { Thickness of the } \\
\text { pseudotachylyte }\end{array}$ & $\sim 1 \mathrm{~mm}$ & $1.1 \mathrm{~mm}$ & $\begin{array}{l}5.2 \mathrm{~mm}(\sim 10 \mathrm{~mm} \text { when it is } \\
\text { doubled, Fig. } 1 \mathrm{c})\end{array}$ \\
\hline Strike displacement & Unknown & $>0.55 \mathrm{~m}$ & $>0.6 \mathrm{~m}$ \\
\hline Orientation of the fault & $\mathrm{N} 217^{\circ} /$ vertical & $\mathrm{N}^{\circ} 90 / 40 \mathrm{~N}$ & $\mathrm{~N}^{\circ} 100$ / vertical \\
\hline $\begin{array}{l}\text { Orientation of the } \\
\text { foliation }\end{array}$ & $\mathrm{N} 36^{\circ} / \mathrm{E} 85^{\circ}$ & $\mathrm{N}^{\circ} 43$ / 40NW & $\mathrm{N}^{\circ} 100$ / vertical \\
\hline
\end{tabular}

552 Table 2. Symbols and parameters used for estimating the dynamic shear stress and cooling duration of

553 the studied pseudotachylytes.

\begin{tabular}{|l|l|l|}
\hline Symbol & Parameter & Value, unit \\
\hline $\mathrm{w}$ & Thickness of the pseudotachylyte layer & $1 \mathrm{~mm}$ to $1 \mathrm{~cm}$ \\
\hline $\mathrm{d}$ & Surface displacement & 0.5 to $0.6 \mathrm{~m}$ \\
\hline$\rho$ & Volumetric mass density & $3020 \mathrm{~kg} \cdot \mathrm{m}^{-3}$ \\
\hline$T_{\mathrm{hr}}$ & Host rock temperature & $650{ }^{\circ} \mathrm{C}\left(873^{\circ} \mathrm{K}\right)$ \\
\hline$T_{\mathrm{i}}$ & Melting temperature of the granulite & $950^{\circ} \mathrm{C}\left(1173^{\circ} \mathrm{K}\right)$ \\
\hline$T_{\mathrm{m}}$ & Maximum temperature of the melt & $1500^{\circ} \mathrm{C}\left(1773^{\circ} \mathrm{K}\right)$ \\
\hline$c_{p}$ & Specific heat of the host rock & $950 \mathrm{~J} \cdot{ }^{\circ} \mathrm{K}^{-1} \cdot \mathrm{kg}^{-1}$ \\
\hline$\kappa$ & Diffusivity of the host rock & $0.48 \mathrm{E}-6 \mathrm{~m}^{2} \cdot \mathrm{s}^{-1}$ \\
\hline$\Phi$ & Fraction of clasts in the pseudotachylyte & 0 \\
\hline $\mathrm{H}$ & Latent heat of fusion of the host rock & $350 \mathrm{E} 3 \mathrm{~J} \cdot \mathrm{kg}^{-1}$ \\
\hline$g$ & Constant of gravity & $9.81 \mathrm{~m} \cdot \mathrm{s}^{-2}$ \\
\hline $\mathrm{P}_{\mathrm{v}}$ & Confining pressure & 1.2 to $1.5 \mathrm{GPa}$ \\
\hline $\mathrm{V}$ & Coseismic slip rate & $1 \mathrm{~m} \cdot \mathrm{s}^{-1}$ \\
\hline$\tau_{\mathrm{d}}$ & Dynamic shear stress during coseismic slip & $\mathrm{Pa}$ \\
\hline$\tau_{\mathrm{s}}$ & Static shear stress prior to faulting & $\mathrm{Pa}$ \\
\hline
\end{tabular}



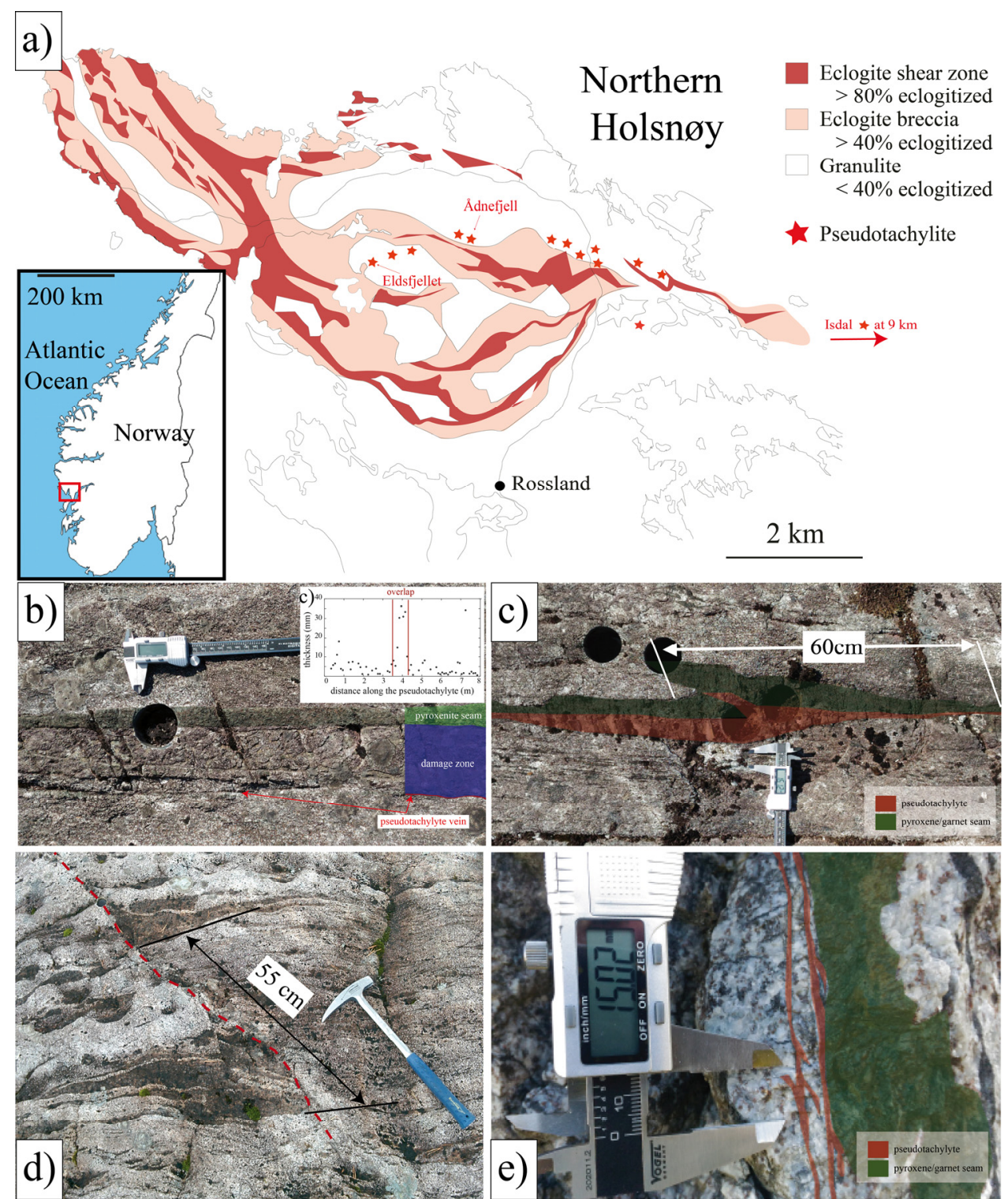

Fig. 1: a) Simplified geological map of Holsnøy Island and location of three outcrops (red arrows) of lower crust fossil earthquakes, Bergen Arc, Norway (modified from Austrheim et al., 1996). GPS coordinates and sample references are given in Table 1. Inset shows map of Norway. The red box shows the location of Holsnøy Island. b-f) Photographs of outcrops of fossil lower crust earthquakes. b, c) Ådnefjell outcrop showing the same pseudotachylyte at two locations ten meter apart; d) Eldsfjellet outcrop (Austrheim et al., 2017); e) Isdal outcrop. Pseudotachylytes, colored in red, appear as dark aphanitic veins in granulite rocks running parallel to the foliation (b, c) or across it (d, e). We recognize pseudotachylytes in the field from injection veins (e), offsets of pyroxene and garnet rich seams (c, d), and a sharp dark layer. Holes in (b) and (c) show the locations where we drilled core samples. We cut a thin section from the lower drill hole in (c). We observe a brecciated damage zone, underlined in dark blue (b) on a side of one pseudotachylyte. This damage zone contains some pseudotachylyte material (not shown). We measured the thickness of the pseudotachylyte (inset in b) every $10 \mathrm{~cm}$ and show the location where the thickness doubles from its average values of $5 \mathrm{~mm}$ in c). 

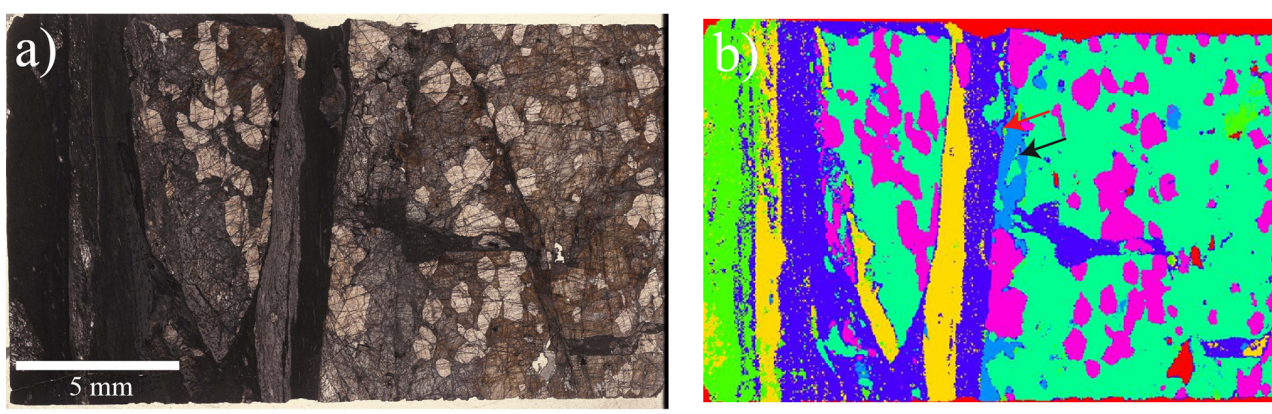

Garnet

Pseudotachylyte

Scapolite

host rock

$\mathrm{Cpx}$

Cpx + garnet

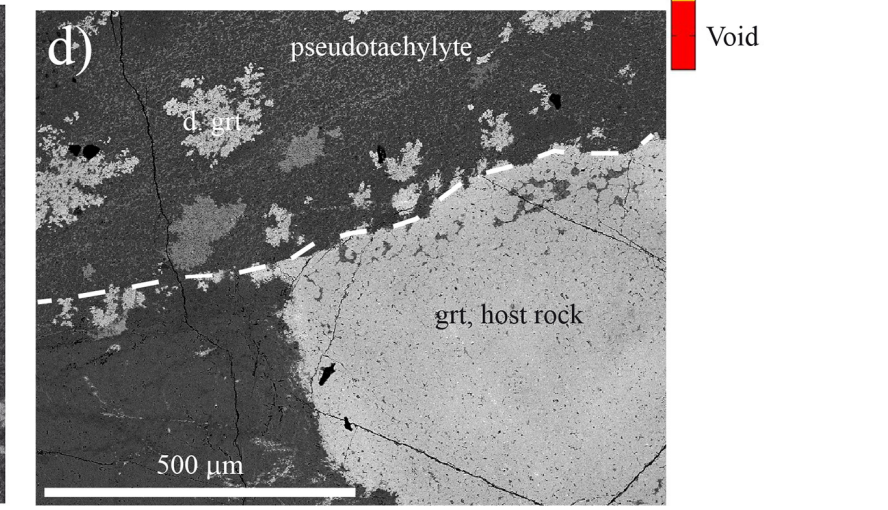

pseudSotachylyte
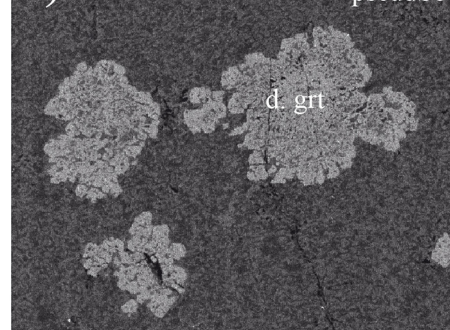

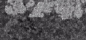

(2)

$100 \mu \mathrm{m}$

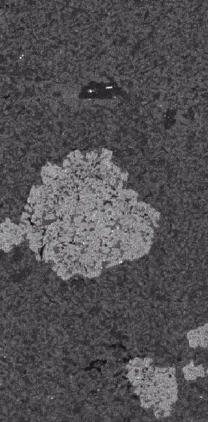

Fig. 2: Microscopic observations of thin sections of pseudotachylytes of the Eldsfjellet (a, b, c) and

571 Ådnefjell (d) samples. a) Optical image in which the pseudotachylyte appears as a dark vein. b)

572 Mineral map produced from X-ray fluorescence chemical maps showing a clinopyroxene (Cpx)-garnet

573 seam crosscut by the pseudotachylyte. Note the presence of scapolite in the wall rock (black arrow)

574 and a fragment in the pseudotachylyte (red arrow). c) Scanning electron microscopy image of dendritic

575 garnets in the pseudotachylytes of the Eldsfjellet sample. The image is taken in the middle of the

576 pseudotachylyte displayed in (a). d) Scanning electron microscopy image of the dendritic garnets in

577 the pseudotachylyte of the Ådnefjell sample. Black dashed line highlights the boundary between the

578 host rock and the pseudotachylyte (d. grt.: dendritic garnet). 

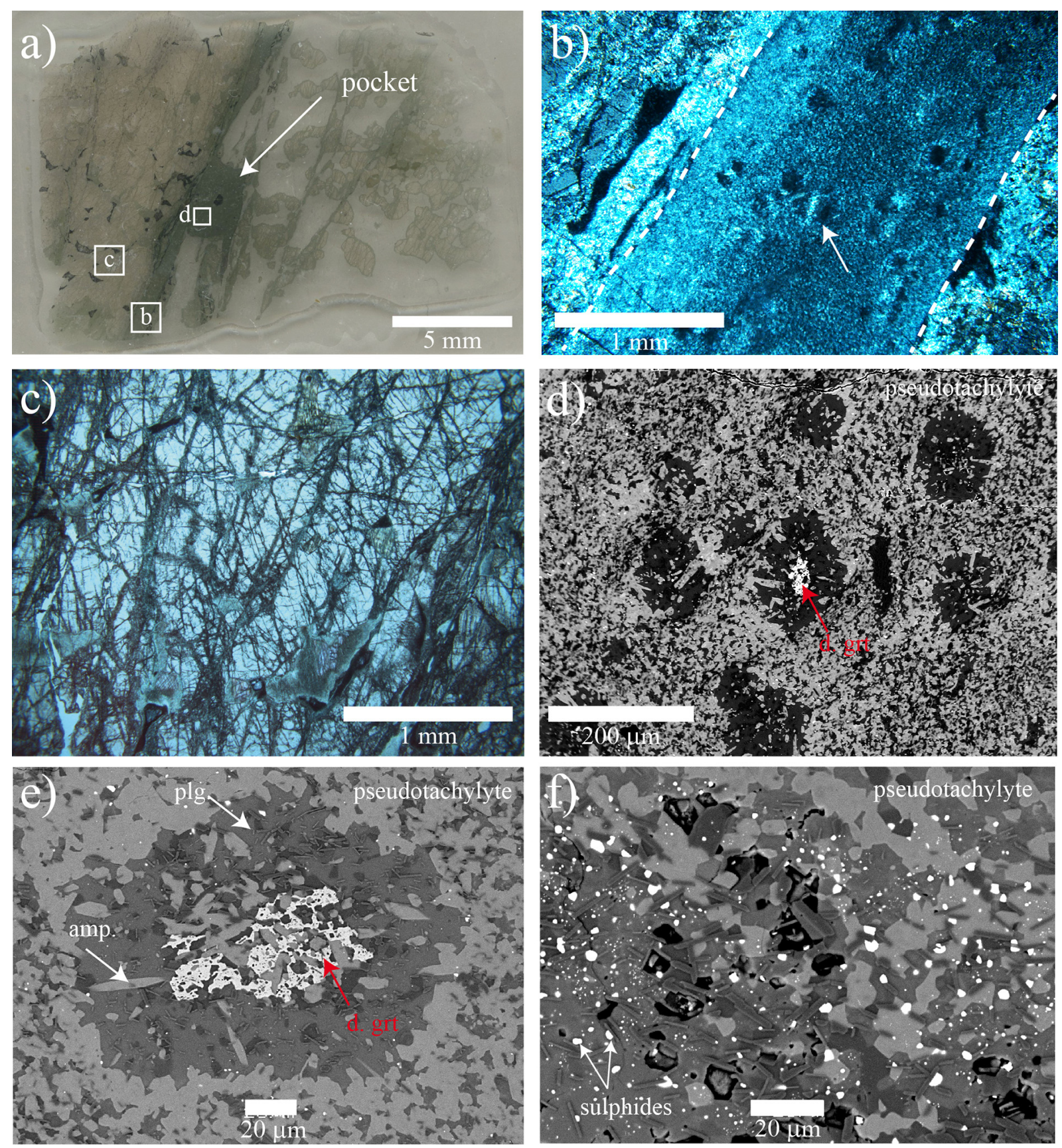

580 Fig. 3: Microscopic observations on the thin section of the pseudotachylyte from the Isdal outcrop

581 (sample HSA2-11, Table 1). a, b) Optical microscopy views in which pseudotachylyte appears as dark

582 vein. We imaged the pseudotachylyte pocket in 3D using X-ray microtomography (see Fig. 5). b)

583 Garnets and their corona (white arrow) appear in the main vein of the pseudotachylyte (underlined

584 with dashed lines). c) The damage of the wall rock (i.e., microfractures) is shown at microscopic scale.

585 d) Electron microprobe back-scattered image highlights the difference in structure between the skeletal

586 garnet core (red arrow) and the plagioclase-rich corona (dark grey). e) BSE image of a skeletal and

587 dendritic garnet core (red arrow), surrounded by the plagioclase corona that contains also small

588 amount of amphibole (amp.). f) Sulphides with droplet shapes in the pseudotachylyte (see also

589 Austrheim et al., 2017). 


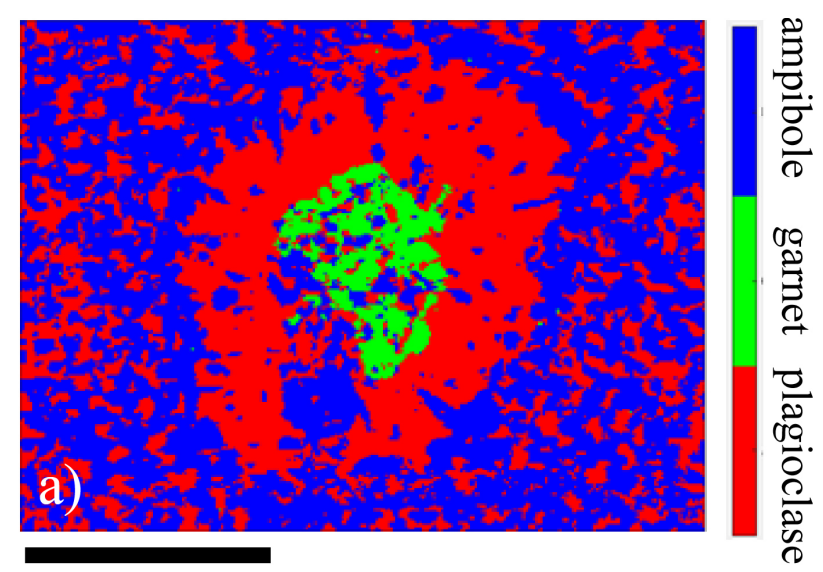

$100 \mu \mathrm{m}$
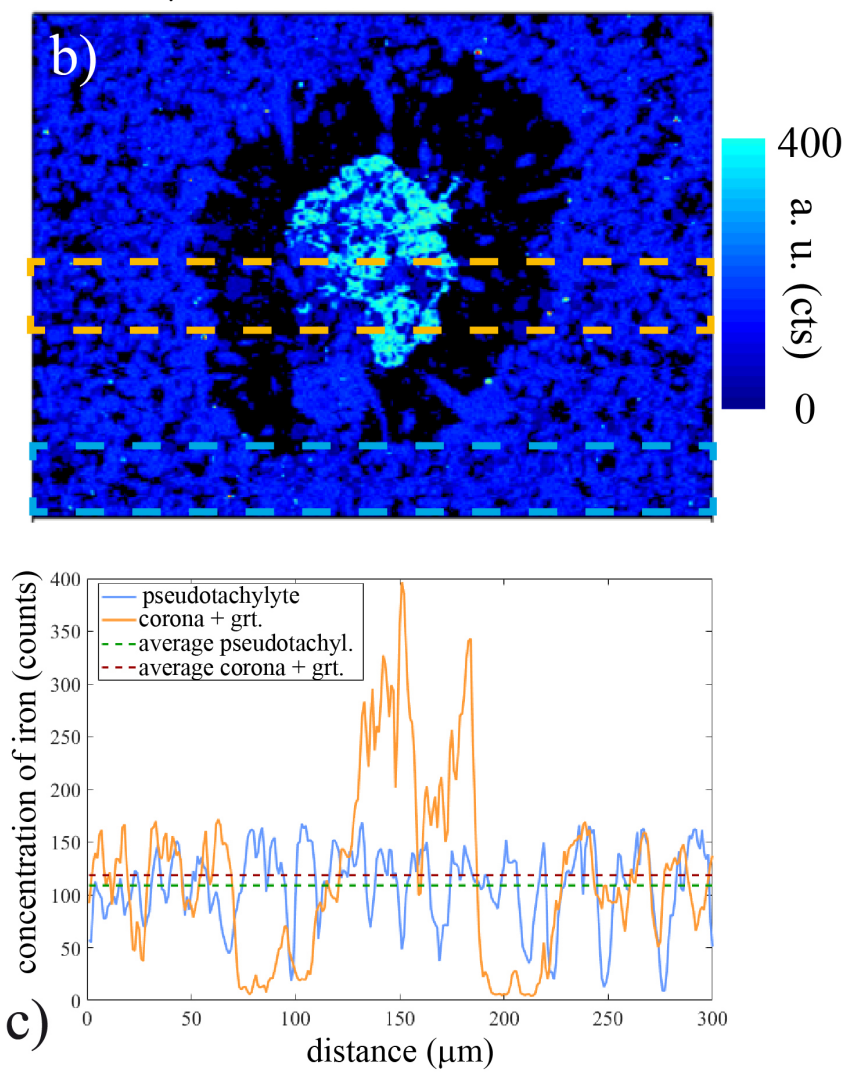

Fig. 4: Representative skeletal garnet and its plagioclase corona in the Isdal pseudotachylyte (sample HSA2-11). a) Mineralogical map produced from electron microprobe analysis data shows the detailed composition of the pseudotachylyte, the garnet and the plagioclase corona. The matrix is composed mainly of plagioclase and amphibole. b) Iron chemical map generated using wavelength dispersive spectroscopy on an electron microprobe. The garnet core is enriched in iron and microcrystals, whereas the surrounding corona is almost fully depleted in iron. c) Concentration profiles of iron, indicated as dashed boxes in (b), show an increase in concentration in the garnet, a depletion in the corona, and a composition in the matrix with an average (green dashed line) that closely matches the average of the garnet and its corona (red dashed line). The similar values reveal an overall conservation of iron at this scale. 

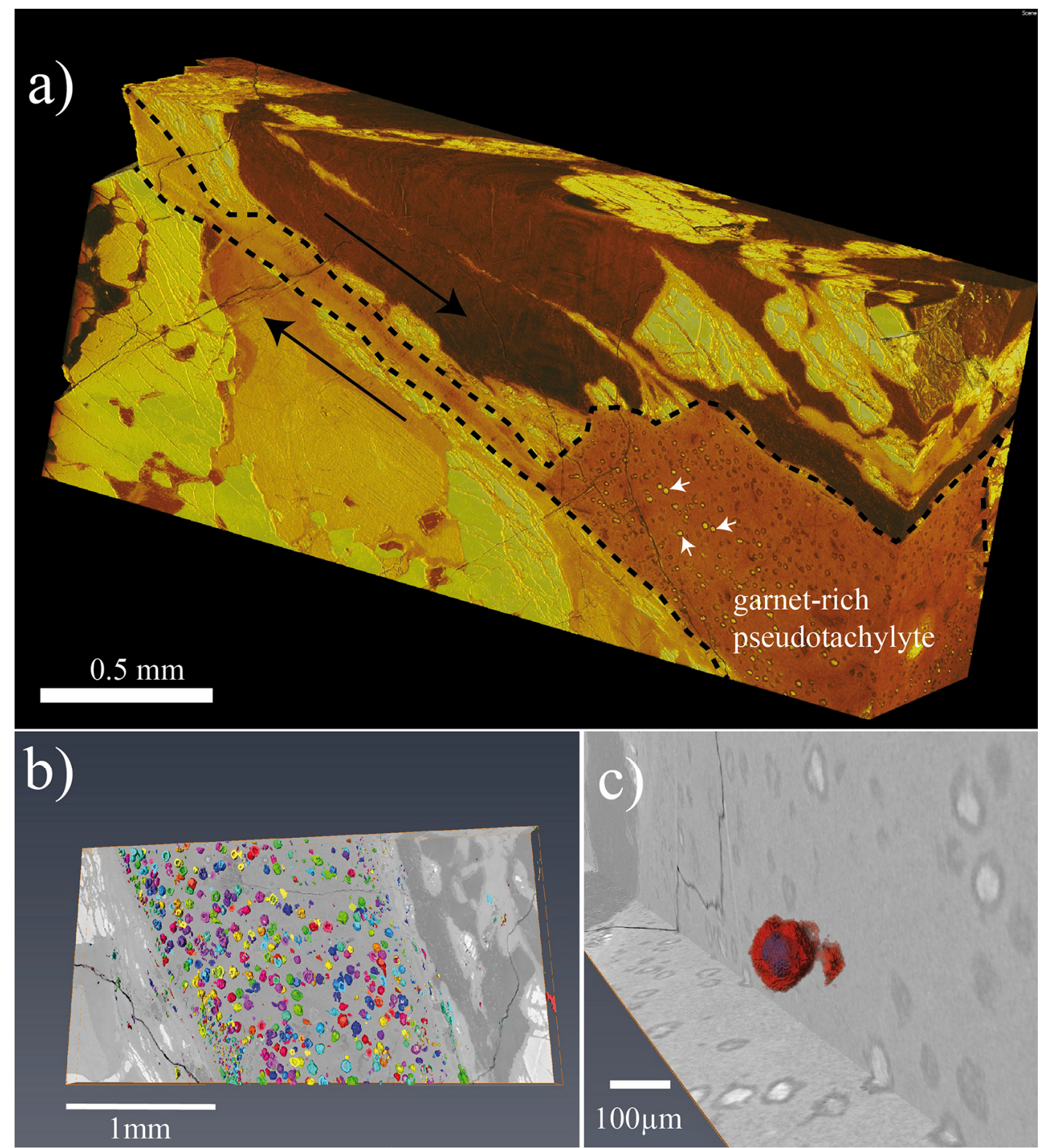

Fig. 5: X-ray computed microtomography imaging of garnets in the pseudotachylyte of Fig. 3. a)

603 Dashed lines outline the borders of 3D rendering of the pseudotachylyte. White arrows point to garnets 604 which have a lighter color, indicating higher density. b) Rendering of the 3D spatial distribution of 605 garnets and coronae. Fewer, larger garnets are located in the center of the pseudotachylyte, whereas a 606 greater number of smaller garnets are located near the boundary with the host rock. Fig. 10 quantifies this observation. c) Single garnet (violet) with its plagioclase-rich corona (red). 


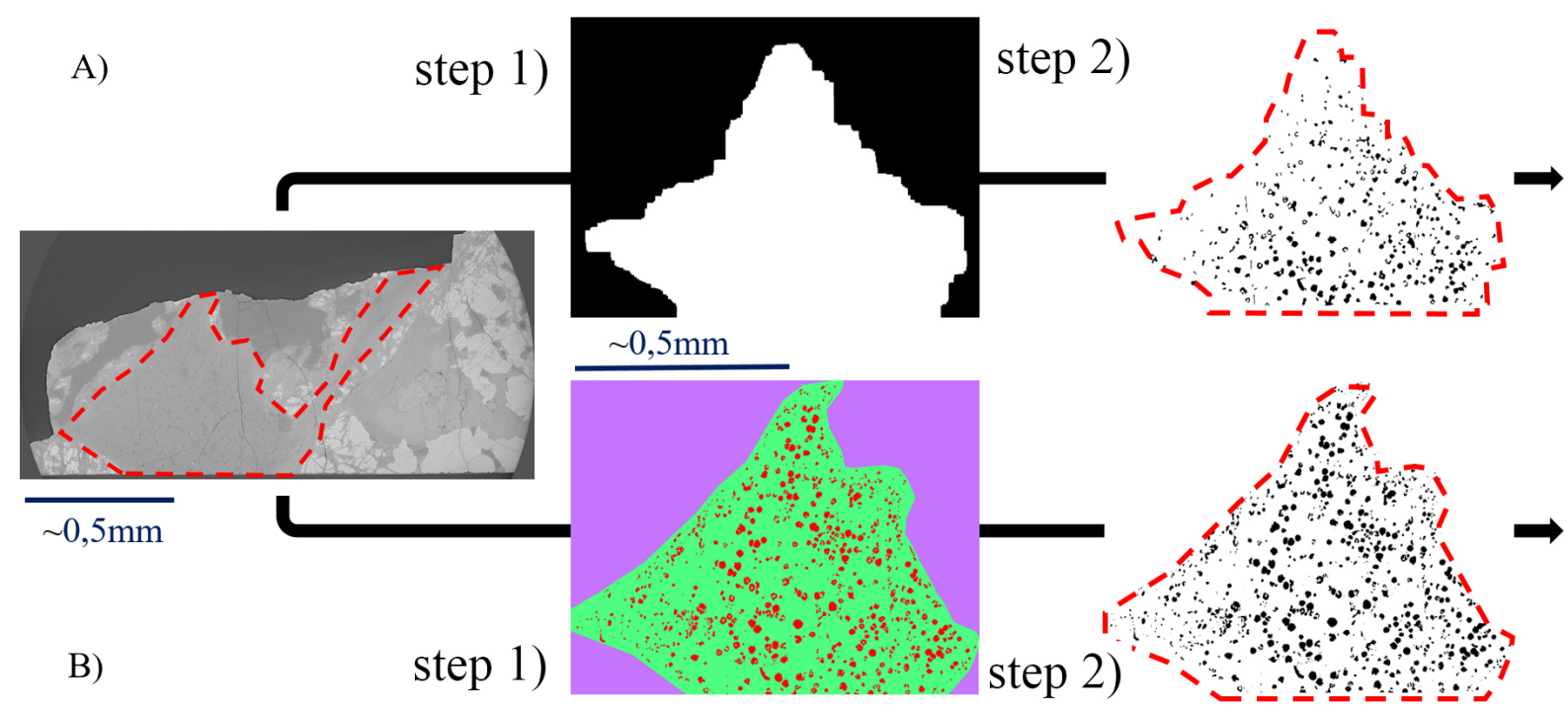

Fig. 6: Image processing method of the X-ray tomography data to extract the crystals in the pseudotachylyte. We used two methods to select either garnet crystals and their corona, or the garnets alone. A) Workflow based on grey level thresholding with the commercial software AvizoFire. First, a mask of the pseudotachylyte area (2D) or volume (3D) removes the host rock from the analysis (A, step 1). Second, thresholding selects the garnets and their corona (A, step 2). B) Workflow based on the Weka machine learning algorithm (Arganda-Carreras et al., 2017) implemented on the image processing open source platform FiJi. The workflow identifies three classes as train features: garnet 616 (red), pseudotachylyte matrix (green), and host rock (violet). Then the machine learning algorithm 617 automatically selects each pixel and assigns it to one of the three classes (B, step 1). This procedure 618 determines the location and volume of each garnet (B, step 2). Dashed red lines highlight the boundary between the pseudotachylyte and the host rock. 


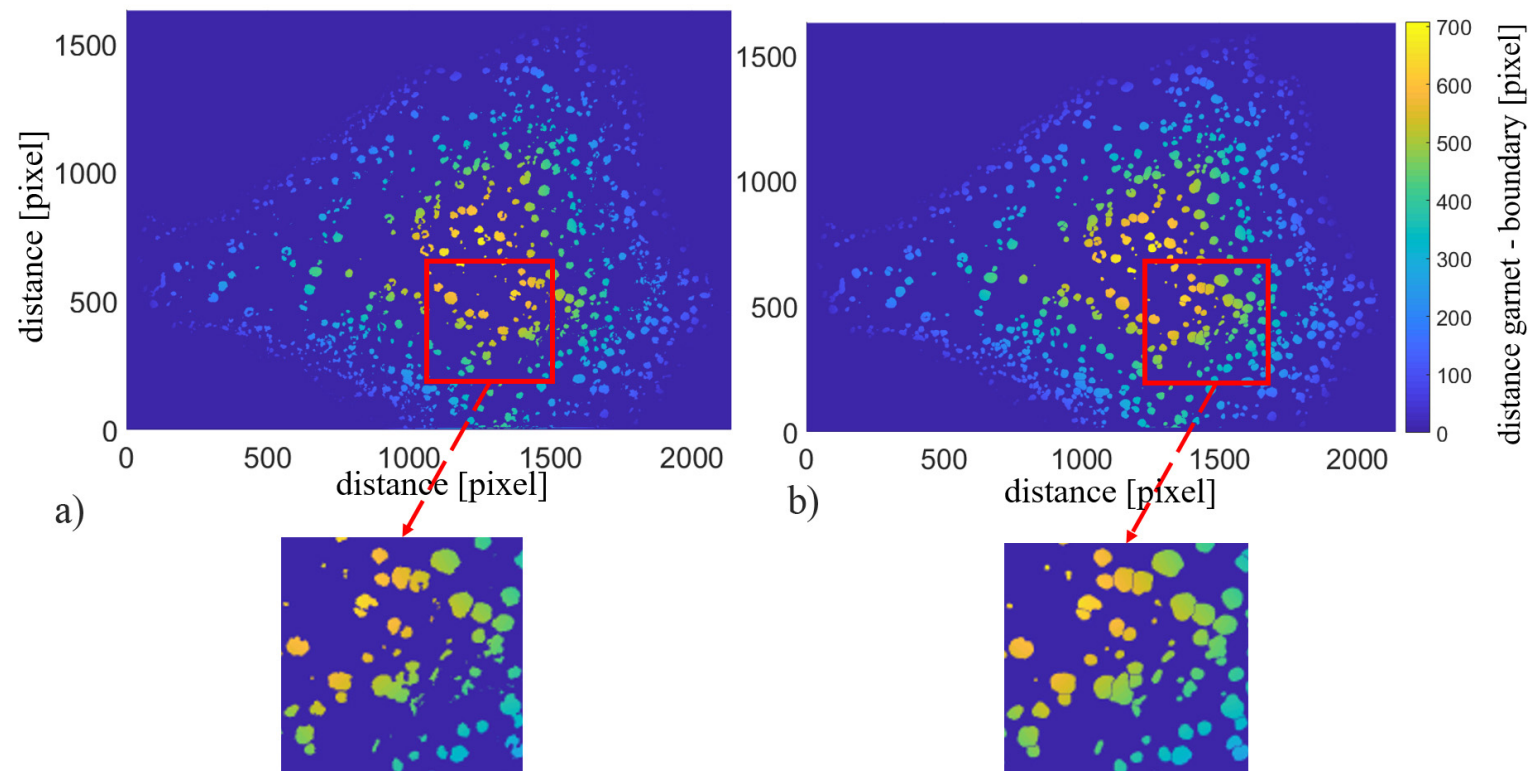

621 Fig. 7: Two procedures to segment the garnets and their coronae. a) Results from thresholding

622 procedure without watershed algorithm. b) Results from using watershed algorithm before

623 thresholding. This two-step procedure improved the identification of individual neighboring garnets

624 that the one-step procedure often identifies as singular larger garnets (see insets). Pixel size: $4.66 \mu \mathrm{m}$. 
a)

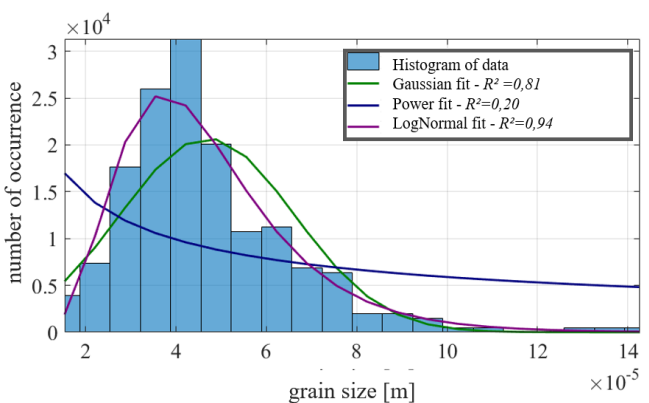

c)

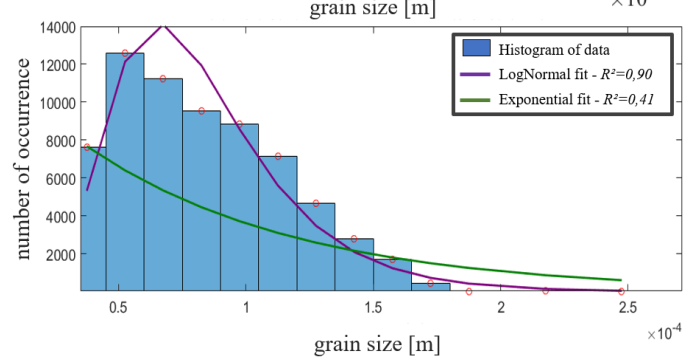

b)

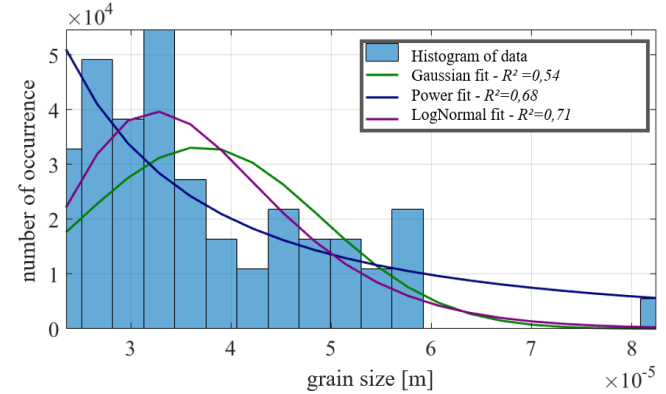

d)

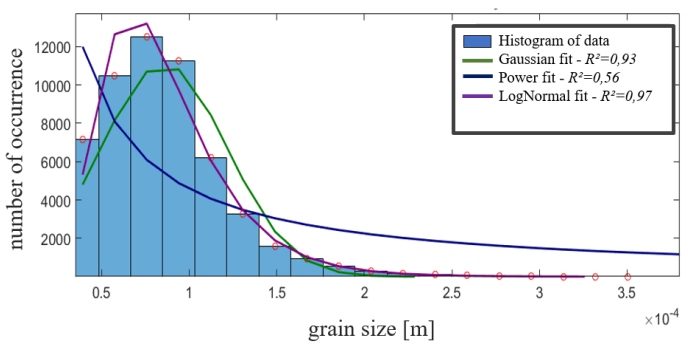

Fig. 8: Histogram of size distribution of garnets and coronae (a) and garnets alone (b) in a 2D section within the pseudotachylyte. c, d) Size distribution of the garnets and coronae based on 3D data. We used two segmentation methods to extract the grains and estimate their size: a machine learning

629 algorithm (a, c) or a simple thresholding procedure (b, d). For the 2D data, we calculated the grain size as the square root of the grain surface area. For the 3D data, we calculated the grain size as the cubic root of the grain volume. A log-normal distribution best fits the data, achieving the highest $\mathrm{R}^{2}$. 

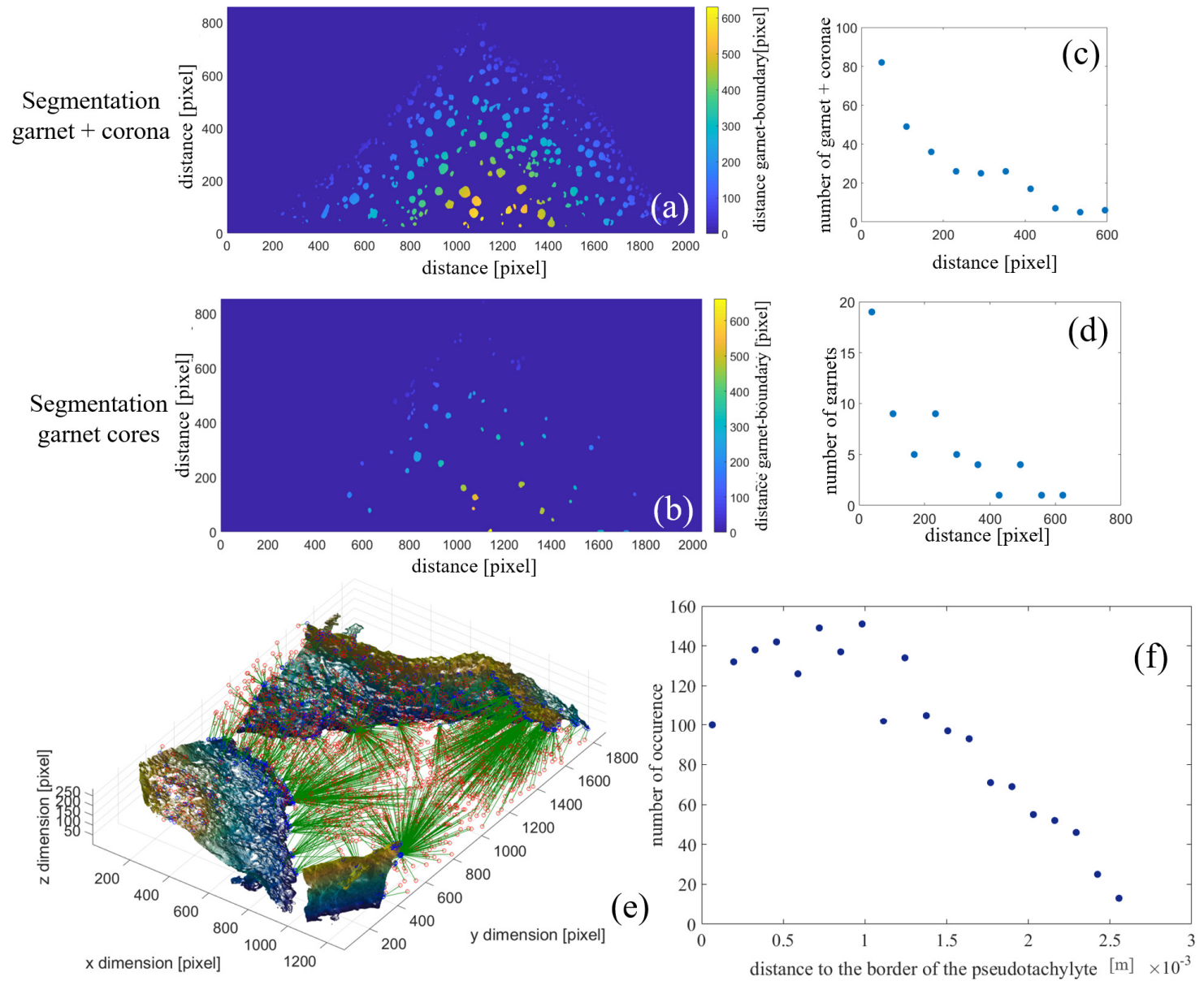

Fig. 9: 2D and 3D spatial distribution of garnets. Garnets and their corona (a, c) or garnets alone (b, d)

634 on a 2D slice, and corresponding histogram of number versus distance to the boundary between the

635 pseudotachylyte and the host rock. (a, b) The artificial color of each garnet or garnet and corona shows

636 how close they are to the host rock-pseudotachylyte boundary. e) 3D view of the shortest distance

637 between each garnet (red dot) and the nearest pseudotachylyte-host rock boundary. f) Spatial

638 distribution of garnets with respect to the distance to the nearest host rock boundary in a 3D volume.

639 Pixel size: $4.66 \mu \mathrm{m}$. 


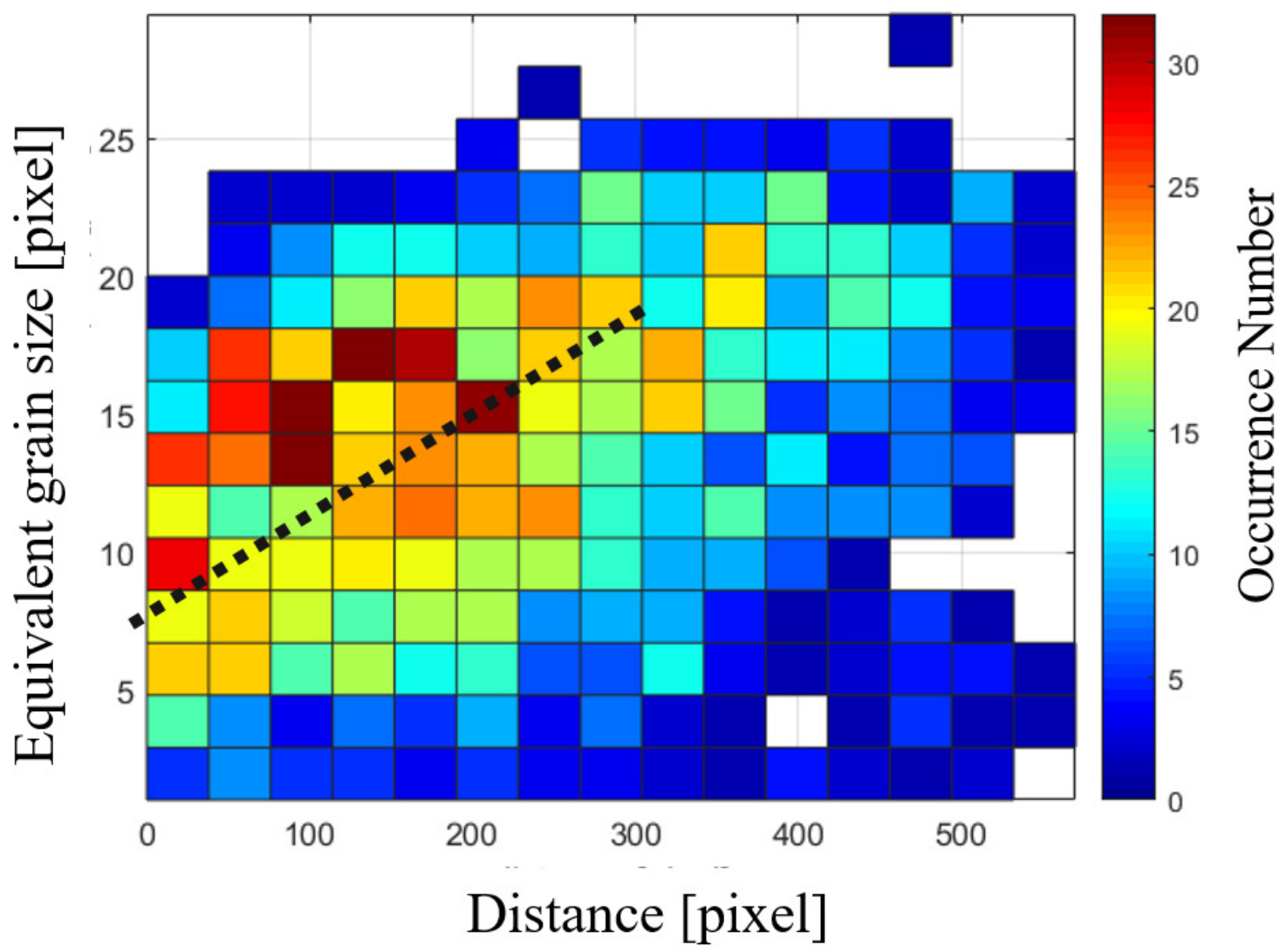

640

641 Fig. 10: Equivalent grain size (i.e., the cubic root of the grain volume) in the pseudotachylyte relative

642 to the distance to the nearest host rock boundary for the garnets without their corona. Larger garnets

643 tend to be located in the middle of the pseudotachylyte. This plot quantifies the data shown in Fig. 5b

644 where we observed 1) smaller garnets located near the host rock wall and larger garnets located near

645 the center of the pseudotachylyte, where the duration of crystal growth was longer; 2) a larger number

646 of garnets near the wall than in the center of the pseudotachylyte. Pixel size: 4 . $66 \mu \mathrm{m}$. 


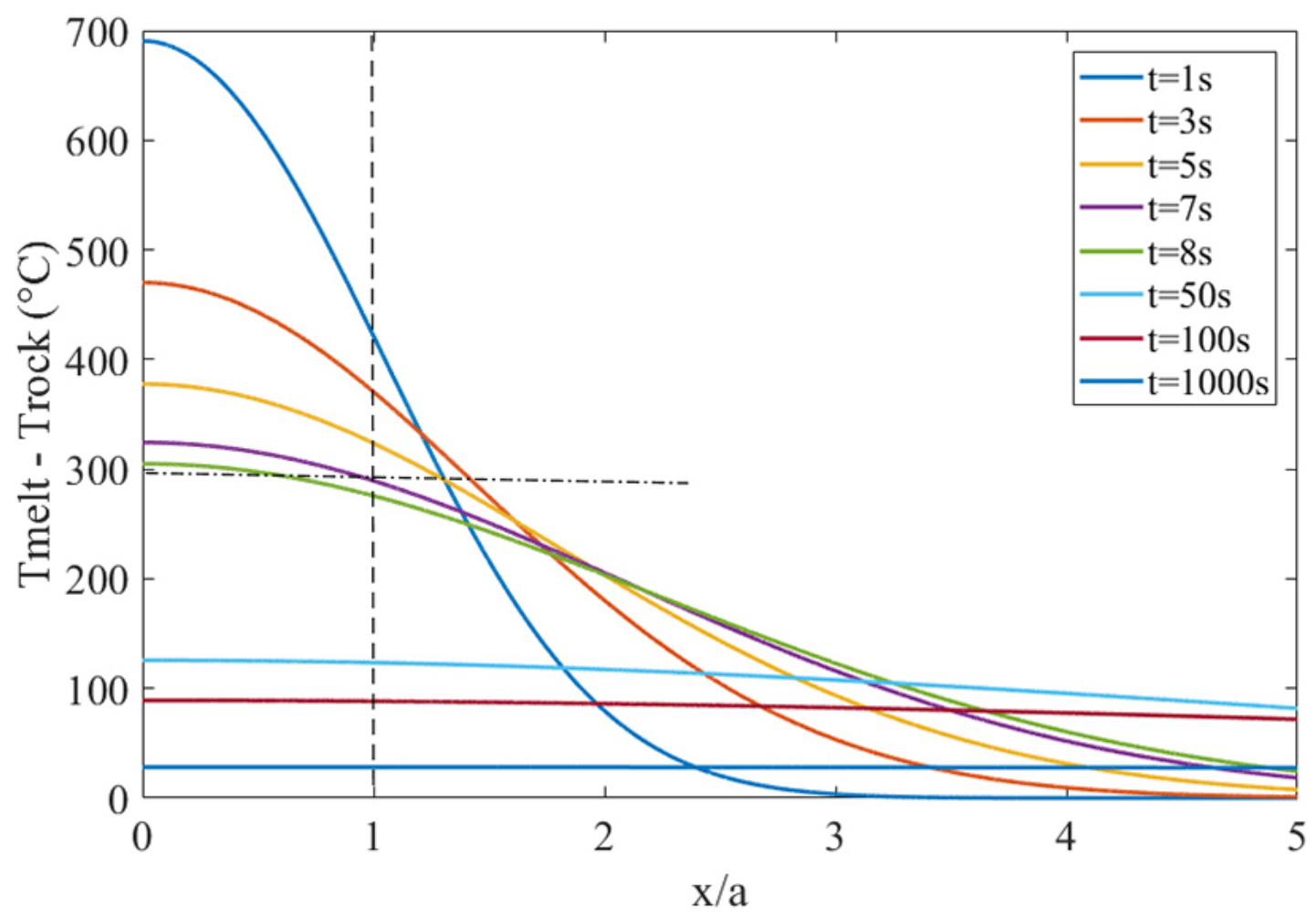

647

648 Fig. 11: Estimates of cooling time of pseudotachylyte. The vertical dashed line at $\mathrm{x} / \mathrm{a}=1$ is the limit

649 between the melt layer of thickness, 2a, and the host rock. The horizontal dashed line shows the

650 temperature at the onset of melting. These estimates suggest that the melt solidified $\sim 7 \mathrm{~s}$ after the melt

651 achieved its highest temperature. 